\title{
Tuberculosis Elimination in Malaysia by 2035: Linkages and Implications to SDGs
}

\author{
Hock Lye Koh, Mohamed Naim Abdul Kadir, Noorliza M. Noordin, and Su Yean Teh
}

\begin{abstract}
Good health and wellbeing (SDG 3) is a fundamental human right for all. The main determinant for good health and wellbeing critically depends on equitable access to good health care (SDG 10) consisting of a combination of strong primary health care (PHC) oriented around community and efficacious public health services (PHS) based upon hospital and professional services. The world including Malaysia has achieved dramatic improvement in the delivery of health services due to advances in socio-economic development. Yet several diseases remain a daunting challenge to sustainable development goals (SDGs). A disease of the poor and the impoverished, tuberculosis (TB) is the leading infectious disease that kills more than a million people each year worldwide. Tuberculosis infection and disease progression are primarily driven by socio-economic and cultural factors such as poor living conditions, poor nutrition and misplaced cultural beliefs. Yet, management of TB has been mainly biomedical, without addressing the socio-economic and cultural drivers, since the 1940s. Given the status of ineffective management, TB will continue to pose a real threat to SDGs, especially among the poor and susceptible populations in many parts of the world, including Malaysia. This paper addresses global issues regarding TB management in the context of SDGs and suggests reorientation of health care towards PHC to accelerate achievement of SDG 3 and other broader SDGs. A detailed case study on Malaysian health care for TB is presented to review the needs for change in TB management strategy. The paper proposes policy and program modification necessary to achieve by 2035 the WHO End TB Strategy goals and UN SDGs.
\end{abstract}

Index Terms-Tuberculosis in Malaysia, primary health care, UN-SDG, WHO End TB strategy.

\section{INTRODUCTION}

About 10 million new cases of tuberculosis (TB) were recorded in 2017 worldwide, with 300,000 and 1.3 million deaths among HIV-positive and HIV-negative individuals respectively [1]. Asia is one of the highest TB-burden regions in the world. The top 8 high TB-burden countries accounted for two-thirds of the global TB cases, and of these 8 countries,

Manuscript received May 7, 2018; revised July 23, 2019. NMN would like to acknowledge support from the Long-Term Research Grant on Latent TB Infection, Ministry of Science and Technology, Malaysia and the Medical Research and Ethics Committee (MREC) of Ministry of Health, Malaysia (NMRR 17-315-34830). This work was supported in part by USM RUI grant \#1001/PMATHS/8011018 awarded to TSY. This paper has no conflict of interest.

H. L. Koh is with the Sunway University, Bandar Sunway, 47500 Subang Jaya, Selangor, Malaysia (e-mail: hocklyek@sunway.edu.my).

Mohamed Naim A. K. is with the Ministry of Health Malaysia, Putrajaya, 62590 Federal Territories, Malaysia (e-mail: drnaim@moh.gov.my)

Noorliza M. N. is the National Public Health Laboratory, Ministry of Health Malaysia, 47000 Selangor Darul Ehsan, Malaysia (e-mail: noorliza.noordin9@gmail.com).

S. Y. Teh is with the School of Mathematical Sciences, Universiti Sains Malaysia, 11800 USM, Pulau Pinang, Malaysia (e-mail: syteh@usm.my). six countries are from Asia. Southeast Asia region has the second highest incidence of TB (226 per 100,000 population) and the second highest mortality rate (32 and 1.4 deaths per 100,000 populations HIV-positive and HIV-negative respectively) in 2017. Tuberculosis disproportionately impacts marginalized populations such as the homeless, prisoners, migrants and people with compromised immune system due to other chronic illnesses including HIV infection. The Millennium Development Goals (MDGs) initiated in 2000 has achieved small progress in reducing TB mortality and TB new incidence. Will the SDG agenda that was started in 2016 do any better in eliminating tuberculosis as set out by the World Health Organization (WHO) End TB strategy? Shete et al. [2] poignantly pointed out that "Being poor increases the risk of falling sick with tuberculosis. Falling sick with tuberculosis also leads to impoverishment that can trigger a downward spiral of worsening health, ongoing tuberculosis transmission, and crippling medical expenses which further entrench poverty". This vicious cycle of TB and poverty would diminish the progress of the SDGs and would negate the achievement of the SDGs' guiding principle of leaving no one behind, particularly the impoverished and the poor all over the world. Reduction of social inequalities (SDG 10), mitigation of climate impacts (SDG 13) and elimination of global conflicts (SDG 16) are the three main challenges to SDGs. These three SDGs are intricately related and interlinked. The WHO End TB Strategy calls for three ambitious targets: (a) reduce deaths by 95\% and (b) reduce new cases by $90 \%$ between 2015 and 2035, and (c) ensure that no family suffers catastrophic expenses. Are these three ambitious targets achievable? Not if commercial protectionism takes precedence over social justice to deny equitable access to critically deeded TB drugs, working against the principle of SDG 10 that calls for social equality [3]. Not if current mediocre progress in TB drug pricing strategy continues to strangulate life out of those in poverty, locked out from equitable access to medical services critical to TB treatment. Not if current TB management strategy and commitment is not commensurate with these ambitious goals because of inadequate political leadership.

Access to affordable tuberculosis drugs, particularly for multidrug-resistant (MDR) strains, have been hampered by rigid and non-inclusive intellectual property rights. For example, given India's massive TB disease burden and level of poverty, and the inadequate funding for MDR-TB, it is pessimistic that India would eliminate tuberculosis by 2025 , despite what was promised by its Prime Minister. On Sept 26, 2018, heads of state gathered in New York at the first United Nations High-Level Meeting (UN-HLM) on tuberculosis with the lofty goal of engaging all sectors to bring about socio-economic and cultural change for the elimination of TB. 
Will this UN-HLM make any difference, beyond mere ambitious political declaration? Tuberculosis is the apex of a myriad of developmental, social, and economic problems that demand long-term unwavering global commitments, which appeared to be sorely lacking in the UN-HLM. By integrating different dimensions and challenges of development, the SDGs are the key drivers of international action on social, economic and environmental determinants of health and social equality. However, because of oversight, the SDGs appear to miss out explicit mention of PHC, as a platform for improving global health care [4]. This omission reflects the disappointing implementation of the Alma-Ata declaration of 1978 over the past four decades. Alma-Ata declaration emphasizes social justice and equitable access (SDG 10) to good health care. The Declaration of Alma-Ata in 1978 was the first international call for primary health care as the main strategy for achieving universal health coverage (UHC) and that governments are responsible for upholding that right [1], [5].

Primary health care is based on three pillars: community empowerment, multi-sectoral policies, and integrated delivery of quality primary care and public health services. It achieves better health outcomes at a lower cost; it drives progress towards achievement of the health targets of the Sustainable Development Goals [6]. Achieving health for all and ensuring health care that is truly universal requires a renewed focus on quality primary health care that is designed around people. The declaration advocates moving away from hospitals, from health professionals, from the disease and instead mandates the recognition that health is not only about illness and medical services but more about the social, economic, and environmental factors that drive the health of individuals and populations. Medical care should be easily accessible where people live and work. The draft Astana Declaration (Alma-Ata 2.0), released in June 2018, reinvigorates the key principles of PHC, emphasising universal health coverage (UHC) as a key determinant for achieving the SDGs. Will Alma-Ata 2.0 (Astana Declaration) be a guiding mile stone or just another tomb stone? Because of the harsh financial reality that TB can inflict on the sick and the poor, purely biomedical or stand-alone public health solutions are inadequate to end the tuberculosis epidemic; and countries must implement social policy and strategy that can protect tuberculosis sufferers from the financial shocks of this deadly disease [2]. In hindsight, it is plainly obvious that the MDG-without a clear mandate for addressing the financial commitment required to combat the harsh reality of TB disease- had achieved so little during the decade of implementation. Will the SDG fall into the same trap?

\section{TUBERCULOSIS PATHOGENESIS AND PROGNOSIS}

Tuberculosis (TB) is a severe and contagious disease caused by members of the Mycobacteria tuberculosis (MTB). Infectious droplets containing MTB nuclei are expelled into the air when persons who have pulmonary or laryngeal TB disease cough and sneeze. These tiny particles can remain suspended in the air for several hours. Transmission occurs when a person inhales droplet containing MTB. The droplet nuclei traverse the mouth and nasal passages, through the upper respiratory tract and bronchi to reach the alveoli of the lungs. Approximately 5\% of patients exposed to MTB progress to active TB disease within 2 years, and another $5 \%$ to $15 \%$ will progress to active $\mathrm{TB}$ disease later in life. Without treatment, $50 \%$ of active TB patients will die within 2 years. The advance in chemotherapy has improved treatment rate for those who adhere faithfully to the treatment regime. Treatment failure may occur because of drug resistance or inappropriate treatment regimen, particularly because of non-adherence to therapy regime. For this reason, in Malaysia for example, the responsibility for adequate treatment has been shifted from the patient to the prescribing doctor and the health authority, following the guideline of WHO's directly observed therapy strategy (DOT). Once exposed to MTB, the bacteria can remain dormant in the infected person without any symptoms. However, MTB can be reactivated years later when the patient's immunologic responsiveness weakens because of old age or immunosuppressive disease, causing the latent disease to become active TB later in life [7]. In theory, one droplet nucleus may be enough to establish infection. In reality, prolonged exposure and multiple aerosol inocula are usually required to cause active infection. Hence, poor living conditions that repeatedly expose potential TB patients to MTB contribute significantly to the transmission of MTB. Thus, TB transmission is intimately linked to poverty and to SDG 3 and other connected SDGs. Elimination of TB is contingent on the elimination of poverty (SDG 1) and on the elimination of social inequality (SDG 10).

Despite major medical advances of the past 50 years, TB remains a leading cause of global infectious morbidity and mortality. The WHO declared TB as a 'Global Emergency' in 1993 and developed the DOT strategy, promising to 'Stop TB' by finding and treating infectious cases in resources-limited settings [8,9]. The World Bank soon labelled the DOT strategy the most cost-effective health intervention ever deployed. Yet, in year 2011, TB caused 1.4 million deaths with 8.7 million new cases detected. By 2012, an estimated 51 million people had been treated and an estimated 20 million lives saved [10], [11]. WHO has estimated that one billion people will be infected, leading to 200 million people developing clinical tuberculosis and 35 million deaths over the next 20 years. WHO dire prediction is premised upon three major threats to global TB Control: (a) Poor social environment including poor living condition and poor nutrition [12], (b) Immunodeficiency related to the HIV pandemic [13], [14], and (c) Emergence of multi-drug-resistant (MDR) TB [15], [16]. Global TB distribution correlates closely with poverty [17], [18], with only $1 \%$ of the global TB burden occurring in the industrially developed countries of North America and Europe while more than $90 \%$ occur in less developed Asia and least developed Africa. HIV-induced immune suppression increases the risk of disease progression from dormant to active TB by nearly 100 folds [19], [20]. Hence, HIV contributes substantially to TB incidence, especially in Sub-Saharan Africa [14]. In 2011, there were over 600,000 prevalent cases of MDR-TB, accounted for approximately $3.7 \%$ of newly diagnosed TB cases and $20 \%$ of relapsed cases globally. Reliable global estimates of MDR-TB are difficult to obtain since rigorous drug-susceptibility testing (DST) is not available in most resource-limited settings. 


\section{Case Study of Tuberculosis Care in Malaysia}

The previous sections presented global perspectives on TB care and its linkages and implications to UN-SDGs and WHO End TB Strategy and provided a framework for the deliberation of TB care in Malaysia. Malaysia has made significant progress since the establishment of the National Tuberculosis Control Program in 1961. The TB burden then was 350 per 100,000 population. The notification rate (NR) was basically stagnant for two decades from 1990 to 2010 with around 60 per 100,000 population. Subsequently, the NR gradually picked up to 80 per 100, 000 by 2016 (Fig. 1). The proportions of new cases and retreatment cases between 2010 and 2015 remained constant at about $7 \%$ and $93 \%$ respectively. Fig. 2 shows age-group specific NR per 100,000 of age-group specific populations, between 2010 and 2015. Percentage of TB among children of less than 15-year-old was 3\%. Percentage TB cases for age-group of 25-54 years and age-group 55 and above were $53 \%$ and $28 \%$ respectively, indicating increasing TB cases as age increases. Among health care workers (HCW), NR of TB increased from 98.4 per $100,000 \mathrm{HCWs}$ in 2011 to 121.5 per $100,000 \mathrm{HCWs}$ in 2015. Fig. 3 shows new cases of MDR-TB in Malaysia, for the period 2004 to 2015 , contributing about $0.5 \%$ to all TB cases. Drug resistant TB continues to threaten global TB control and remains a major public health concern in many countries including Malaysia. Globally for 2014, WHO estimated about $3.3 \%$ (95\% CI: $2.2-4.4 \%)$ of new cases and $20 \%$ (95\% CI: $14-27 \%$ ) of previously treated cases with MDR-TB. Table I shows TB cases and incidences in prisons, and in general population in Malaysia for the period 2011 to 2015. As can be seen in Table I, TB remains a critical health problem in prisons, with incidence rates almost ten times of the general population. Regarding HIV, out of a total of 21,296 (87.9\%) notified TB cases that underwent HIV screening, 1346 cases $(6.3 \%)$ were found to be HIV-positive (1,234 pre-diagnoses and 112 post-diagnoses) [21]-[24].

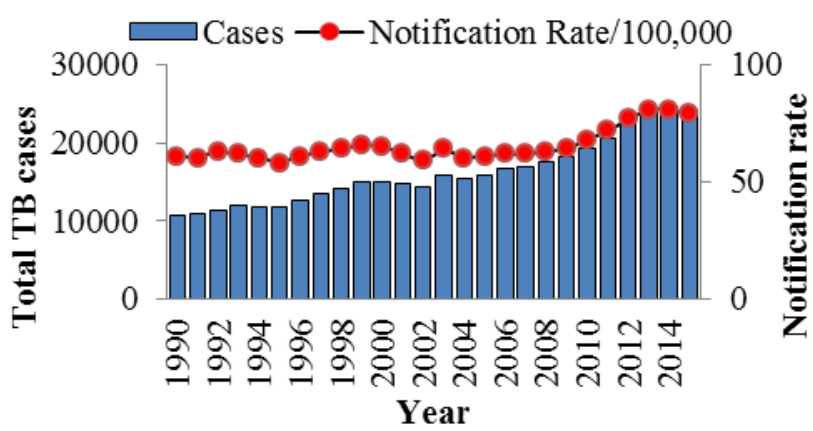

Fig. 1. Notification rate (NR) of TB for Malaysia (1990-2016).

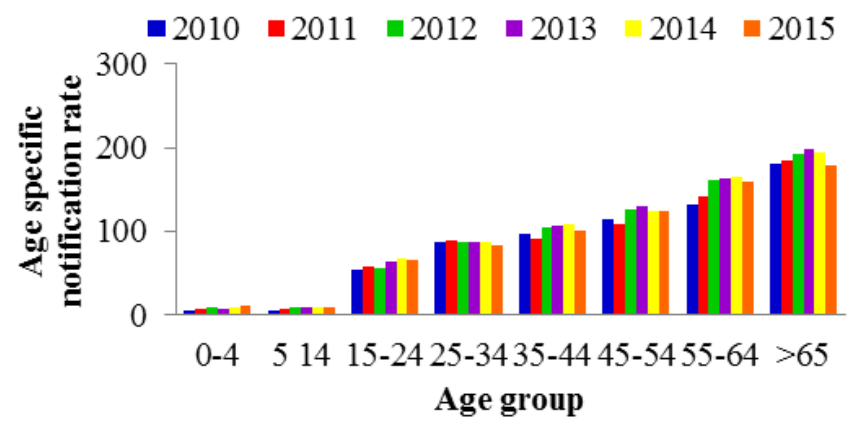

Fig. 2. Age group specific notification rate per 100,000 of age group specific populations, 2010-2015.

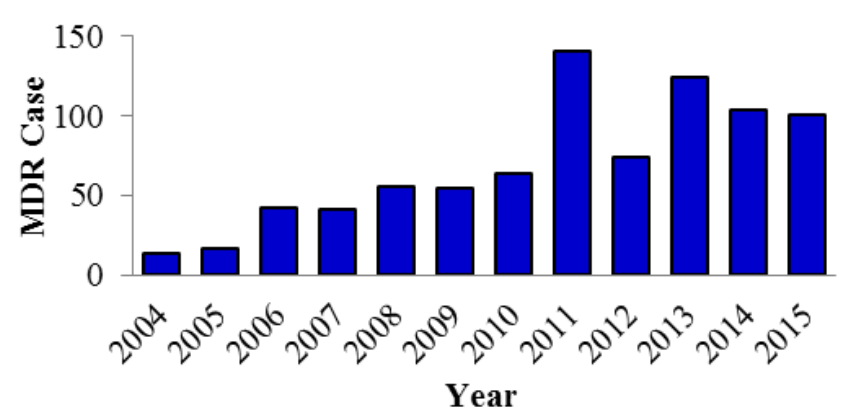

Fig. 3. Cases of MDR-TB, Malaysia (2004-2015).

TABLE I: TB CASES AND INCIDENCE IN PRISONS, MALAYSIA (2011-2015)

\begin{tabular}{ccccc}
\hline \hline Year & $\begin{array}{c}\text { TB cases } \\
\text { in prison }\end{array}$ & $\begin{array}{c}\text { TB Incidence } \\
\text { in prison (per } \\
100,000 \\
\text { population }\end{array}$ & $\begin{array}{c}\text { TB cases in } \\
\text { population }\end{array}$ & $\begin{array}{c}\text { Incidence in } \\
\text { population (per } \\
100,000 \\
\text { population) }\end{array}$ \\
\hline 2011 & 272 & 774.8 & 20666 & 71.3 \\
2012 & 231 & 608.0 & 22710 & 77.4 \\
2013 & 219 & 518.2 & 24071 & 81.0 \\
2014 & 340 & 683.6 & 24711 & 82.1 \\
2015 & 344 & 653.8 & 24220 & 79.4 \\
\hline \hline
\end{tabular}

\section{TuBERCUlosis ACHIEVEMENT, GAPS AND CHALLENGES IN MALAYSIA}

The Malaysian National Tuberculosis Programmes (NTPs) have expanded the TB control strategy, putting the focus on early case detection among symptomatic and high-risk patients, on ensuring quality laboratory services, on development of training module, guidelines and MyTB databases, and on conducting regular training courses to staffs, coupled with strengthening collaboration with other agencies to improve synergy. Actual detection of TB cases in Malaysia remains below the estimated figure by WHO. The WHO Global Tuberculosis Control 2015 reported that estimated incidence rate for Malaysia (2014) was 103 per 100,000 populations, whilst actual record was 81 per 100,000 populations, implying that about 6000 cases remain undetected. As seen in Fig. 4, it is projected that TB incidence in Malaysia will continue to increase from 14,000 in 1990 to 31,000 cases by 2030 . Using predicted data between 1990-2010 and actual notification data between 1990-2014, the annual mean under-representation is $13.49 \%$ (95\% CI: $10.39-15.84 \%$ ). To reduce burden of TB in Malaysia according to WHO End TB Strategy by 2035, more pro-active and intensified case-finding activities need to be implemented. Contact tracing is one of the core activities that has been implemented in Malaysia to control TB transmission. Table II shows the achievement of contact TB screening in Malaysia for the period 2009 to 2015. Follow-up of contact of index TB cases should be at the $0,3,6$ and 12-month interval. In 2014, about 178,085 (72.1\%) contacts were identified and screened for TB out of 247,110 contacts of index TB. Contact tracing activities need to be strengthened especially involving congregate setting. About $5 \%$ of $\mathrm{TB}$ cases are detected and managed by private healthcare facilities. Collaboration between public and private healthcare facilities needs to be strengthened for screening of symptomatic TB and optimal care of the TB patients. The high-risk groups susceptible to TB include HIV-patients and persons with medical conditions such as 
diabetic, rheumatoid arthritis, chronic renal failure, chronic obstructive pulmonary diseases, smokers and the elderly. Systematic screening of these high-risk groups will be strengthened to increase case detection rate and to reduce TB transmission. More pro-active approaches need to be implemented to reach the vulnerable group such as the homeless, immigrants and prisoners in Malaysia.

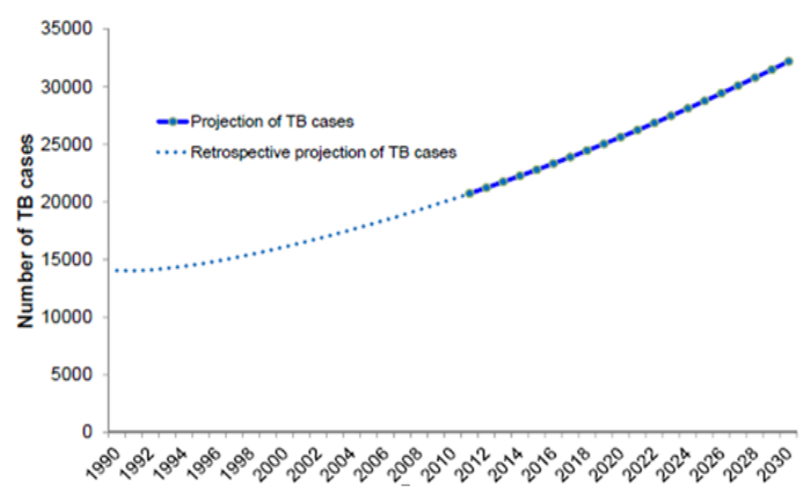

Fig. 4. TB projection in Malaysia (1990-2030).

TABLE II: ACHIEVEMENT OF CONTACT TB SCREENING, MALAYSIA (2009-2015)

\begin{tabular}{cccc}
\hline \hline Year & TB cases & Contact examined & Index case: Contact \\
\hline 2009 & 18,102 & 69,879 & $1: 4$ \\
2010 & 19,337 & 74,426 & $1: 4$ \\
2011 & 20,666 & 87,265 & $1: 4$ \\
2012 & 22,710 & 90,275 & $1: 4$ \\
2013 & 24,071 & 12,2091 & $1: 5$ \\
2014 & 24,711 & 179,136 & $1: 7$ \\
2015 & 24,220 & 189,337 & $1: 8$ \\
\hline \hline
\end{tabular}

Regular updates of the MyTB online system for TB cases, contacts, treatment outcome and mortality pose new challenges, given the limited human resources. Additional manpower is needed especially in the states with high TB cases. Strengthening of TB units at district and clinic levels is justifiable for effective TB Control Programme. The Ministry of Home Affairs, through its Prison Department, is responsible for TB control activities in the penitentiary system. Case detection in the penitentiaries combines passive case finding and active case finding (at entry and regular screening). TB treatment in prisons is provided by medical assistants and doctors. TB-HIV collaborative activities between the National TB Control Programme and the National HIV/AIDS Control Programme were initiated and are continued through joint programme meeting and technical consultations. Collaborative activities include adjustment of guidelines and case management protocols, and collaboration and coordination of activities related to the provision of HIV counselling and testing for TB patients.

Over the last decade, significant progress has been achieved in treatment outcomes of TB cases. Cure rate of pulmonary smear-positive TB cases increased from $67 \%$ in 2009 (cohort 2008) to $77.0 \%$ in 2015 (cohort 2014). The full cohort analyses of the 2014 cohort of new AFB-positive cases are as follows: treatment success: $78.1 \%$, default: $4.9 \%$, failure: $0.2 \%$, death: $9 \%$, not evaluated: $7.5 \%$. Regarding the management of drug-resistant TB, all smear-positive cases are required to send specimen for drug susceptibility test (DST). Malaysia ensures universal access to diagnosis and treatment of all forms of $\mathrm{TB}$, including treatment of extensively-resistant forms of the disease (XDR-TB). Newly developed anti-TB drugs such as Bedaquiline have been used as treatment for XDR-TB patients. Poor treatment outcomes of MDR/XDR-TB patients are the major concern for the national program. Treatment outcome for MDR-TB treatment cohorts 2013 were: $61.7 \%$ successfully treated, $17.6 \%$ died, $1.5 \%$ failed treatment, $14.7 \%$ loss follow up and $4 \%$ of cases were not evaluated at the end of treatment. The very high rates of treatment interruption are attributed by the difficulties by patients to complete the lengthy (up to 2 years) course of therapy due to social and economic circumstances and to insufficient adherence support. Other factors contributing to treatment interruption include medical complications related to adverse drug reactions caused by second-line TB drugs, and failures of health care providers to manage these complications effectively [21]-[24].

\section{TUBERCUlOSIS EliminAtion In MALAysia: THE WAY FORWARD}

Malaysia is classified as a country with an intermediate level of TB burden with notification rate (NR) for TB at less than 100 per 100,000 populations, based upon the standardized TB recording and reporting system. Since 2003, individualized recording and reporting has been put in place and is incorporated in the national electronic TB database. Patients can access for TB treatment and management for free at any health clinics in the country. TB control services in Malaysia have undergone substantial improvement over the last decade. TB laboratories have been strengthened and integrated into the network of public health laboratories under the management of the National Public Health Laboratory (NPHL), Ministry of Health in Sungai Buloh. Currently, there are four regional public health laboratories located in the states of Johor, Perak, Kelantan and Sabah with the entire network supervised by the NPHL in Sungai Buloh. The novel Xpert MTB/RIF diagnostic technology was introduced in 2014 and is being expanded, with 14 machines distributed over the country. The increasing number of TB new incidence poses a great challenge to controlling $\mathrm{TB}$ transmission in Malaysia. Although diagnosis and treatment are provided free to all Malaysians, many TB patients still suffer from heavy financial burden. In addition to several hidden costs, TB patients and their families must bear the cost of transportation, room and board while travelling to the clinic for direct observation of treatment and to endure the prospects of losing their jobs. This will adversely affect the compliance and hence treatment outcome of TB patients. Ensuring DOT is the goal for all TB patients in Malaysia. To support this, incentives are provided to the patients by the Malaysian Association for the Prevention of Tuberculosis (MAPTB) and government to increase adherence to treatment [21]-[24]. However, this piecemeal stand-alone approach is inadequate to achieve the WHO ambitious goal of End TB strategy. The time is ripe to call for a re-examination of current policy and programs. We should put in place social protection scheme for TB patients.

We should go beyond piecemeal program of subsidy and explore a broader-based social protection scheme and integrate it with community-centred primary health care. This will require formulation of new policies, programmes, 
outreach and research to optimize resource utilization. Evidence has emerged to show that countries that re-orientate their health care towards primary care that are focused on community are better placed to achieve medical goals and the SDGs than those with hospital-focused systems [3]. A broadly and community based primary health care could deliver substantially better health objectives and greater SDG progress, by addressing the wider determinants of health, and by promoting equity, human dignity and social justice throughout society. Recent research has estimated that expanding social protection coverage could reduce the global incidence of tuberculosis by $76 \%$ by 2035 [25]. This level of achievement is possible for Malaysia, given the moderate TB burden. This commendable reduction of $76 \%$ is close to the WHO End TB goal of $90 \%$ reduction in new TB incidence. New trials are underway to find shorter and less debilitating treatment regiments for MDR tuberculosis, in this complex and centuries-long fight against this cruel disease. To effectively treat MDR-TB, the full implementation of flexibilities in intellectual property rules geared towards maximising access should be the new normal. This flexibility should give priority to least developed countries, while not neglecting the developing ones. However, under pressure from the USA and others to protect their commercial interests, this noble relaxation of intellectual property right to save life may be subject to strong objection. Social justice must take precedence over commercial profits, as mandated by SDG 10 that calls for social equality and inclusiveness. As a notable example, South Africa becomes the first country in the world to roll out bedaquiline to all eligible patients with MDR tuberculosis at a reduced price. Improving access to adequate medical care and affordable medicines by improvising intellectual property flexibilities is a critical step towards SDG 3 fulfilment.

Empowering communities will achieve synergies among multiple SDGs. By shifting priorities to community-based health system, primary care also targets risk factors and harmful social behaviours that contribute to poor health, such as diabetes, hypertension, low physical activity, poor diet, smoking and excessive alcohol consumption, with benefits for non-communicable diseases too [26], [27]. Primary health care based upon individual medical home care can be integrated seamlessly with specialty, diagnostic and hospital care, protecting patients from unnecessary examinations and treatments. Therefore, countries with strong primary care have been found to have better and more equitable health outcomes and more efficient health system [28]-[30], and can contribute more to SDGs. Poor health, morbidity and mortality associated with deadly infectious diseases such as TB can contribute to impoverishment, defeating SDG 1. It might curtail quality education by attrition or diversion of attention and resources, limiting the achievement of SDG 4. In bad cases, it will hurt employment opportunities, denying access to SDG 8, and contribute to malnutrition (SDG 2). These conditions often affect the most disadvantaged and marginalized sub-populations, further increasing social inequality (SDG 10) within or among countries [31-33]. Primary care services are large employers providing meaningful jobs, in support of SDG 8 . They demand a highly educated workforce, and contribute to the development of quality education (SDG 4), and provide life-long continuing professional and educational development opportunities [34]. Where women compromise a large part of the health system workforce, primary care can promote female empowerment and enhance gender equality (SDG 5). Although health services are large energy consumers and polluters, a large proportion of this energy consumption and pollution comes from hospitals and not from primary care services $[35,36]$. Hence, prioritizing primary health care could save energy consumption, contributing to SDG 7.

\section{DISCUSSION}

The WHO 'End TB strategy' aims to reduce TB deaths by $95 \%$ and to lower the incidence of new TB cases by $90 \%$ between 2015 and 2035 [37]. To achieve this milestone, especially in high TB-burden regions, it is crucial to prevent the development of active TB from inadequate treatment of latent TB. Several approaches could contribute to the achievement of the WHO milestone: increase active TB case detection and proper treatment, optimize active contact-tracing, treat latent TB infection (LTBI), and identify and address the key gaps in LTBI diagnosis and treatment $[1$, 38-40]. The WHO LTBI targets to achieve $\geq 90 \%$ LTBI treatment coverage by 2025 [37]. Latent TB infection is a state of persistent immune response to stimulation by $M$. tuberculosis antigens without evidence of clinically manifested active TB [40]. About $10 \%$ of individuals infected with $M$. tuberculosis are estimated to develop clinically active TB disease and $90 \%$ remain in the latent phase. This large reservoir of individuals with LTBI has a high risk of developing active TB. The particularly vulnerable LTBI individuals are persons who are in constant contacts with active TB patients. [41,42]. Southeast Asia is a major contributor to the LTBI reservoir, with the highest LTBI prevalence rate at $30.8 \%$, compared to $27.9 \%$ in the Western Pacific region, $22.4 \%$ in the African region, $16.3 \%$ in the Eastern Mediterranean region, $13.7 \%$ in Europe, and $11 \%$ in the region of the Americas. China and India have been reported to have the highest LTBI burden ( $\sim 350$ million LTBI cases) followed by Indonesia ( 120 million LTBI cases) [38]. Thus, LTBI remains a major obstacle to achieving WHO Goal to End TB by 2035.

Addressing the global tuberculosis burden will require enhancement in biomedical technology, in conjunction with socio-economic and cultural re-orientation for change. It will need multi-sectoral coordination and action involving the health and other governmental sectors. It must involve the participation of the civil society, especially the poor and susceptible populations. As TB is underpinned by socio-economic, cultural and environmental factors, a biosocial approach, in conjunction of a strong primary care is required to end TB. While $\mathrm{UHC}$ is essential to ending $\mathrm{TB}$ epidemic, UHC in high-burden countries by itself is insufficient to address the TB epidemic. High-burden countries are usually associated with abject poverty that require financial rescue in time of TB infections. Hence, social protection interventions that prevent or mitigate catastrophic financial risks associated with $\mathrm{TB}$, such as income losses and non-medical expenditures, must also be considered [43]. Examples of social protection interventions include cash transfers and nutrition programmes offered by 
individual clinics to social welfare systems adopted as part of national policies. They can contribute to successful TB outcomes through addressing biosocial and economic determinants, and through equitable access to health care [44] Ecological and modelling studies suggest that countries that increase spending on social protection programmes have an associated decrease in tuberculosis incidence and prevalence, and a reduction in mortality [25], [45]. Recent models leveraging data from 192 countries to link the SDG targets to tuberculosis outcomes, suggest that expanding social protection schemes to all eligible populations could decrease tuberculosis incidence by $76 \%$ [25], underlining its immense contribution when used in tandem with proven biomedical interventions. Additional research that incorporates the implementation of science, health economics, and social epidemiology is needed to identify and design feasible, scalable social protection interventions that are context-specific. Finally, policies need to be established to give national tuberculosis programmes the support and mandate necessary to address the socioeconomic consequences of illness for their patients [2].

\section{CONCLUSION}

Tuberculosis remains the leading source of infectious disease mortality globally, responsible for more than one million deaths each year. The WHO End TB Strategy and the UNSDGs are inter-linked by their common targets and approaches. Both have prioritized ending the epidemic of tuberculosis by 2030 . Reducing poverty and health inequality remains a global imperative, enshrined in the United Nation Sustainable Development Goals. Ending extreme poverty and expanding social protection coverage by 2030 as stipulated for SDG 1 will significantly reduce the tuberculosis epidemic through a range of pathways. Catastrophic costs arising from tuberculosis are very common in the lower income countries such as India, many Southeast Asian countries and Sub-Sahara Africa. Alleviation of tuberculosis-induced catastrophic costs remains a major challenge confronting SDG. The success of End Tuberculosis by 2030 is contingent on a commitment to financial risk protection, on equitable access to quality health care and on the use of safe, effective, and affordable diagnostics and medicines. Current efforts are missing millions of people with tuberculosis each year. Strengthening of national surveillance systems to capture all tuberculosis cases in their early stage is an important public health goal for Malaysia and for all countries. Ending tuberculosis is possible with better science, improved health care, adequate and sustainable financing, and strong political will.

\section{ACKNOWLEDGMENT}

The authors would like to thank the Director General of Health Malaysia for permission to publish this paper and to record our sincere gratitude to National TB Control Section officers who have contributed towards the publication.

\section{REFERENCES}

[1] WHO (2018). Global tuberculosis report 2018. World Health Organization. [Online]. Available: http://www.who.int/iris/handle/10665/274453.
[2] P. B. Shete, M. Reid, and E. Goosby, "Message to world leaders: We cannot end tuberculosis without addressing the social and economic burden of the disease," The Lancet Global Health, vol. 6, pp. e1272-e1273, September 2018.

[3] S. Lewis, "A new era for tuberculosis?," The Lancet Global Health, vol. 6, pp. e1045, October 2018.

[4] T. Hone, J. Macinko, and C. Millett, "Revisiting alma-ata: What is the role of primary health care in achieving the Sustainable Development Goals?," The Lancet, vol. 392, pp. 1461-1472, October 2018.

[5] UNICEF. (1978). Alma-Ata 1978 Primary Health Care. Report of the International Conference on Primary Health Care Alma-Ata, USSR, 6-12 September 1978. United Nations International Children's Emergency Fund. [Online]. Available: https://www.unicef.org/about/history/files/Alma_Ata_conference_197 8_report.pdf.

[6] T. A. Ghebreyesus, H. Fore, Y. Birtanov, and Z. Jakab, "Primary health care for the 21st century, universal health coverage, and the Sustainable Development Goals," The Lancet, vol. 392, pp. 1371-1372, October 2018.

[7] J. L. Flynn and J. Chan, "Immune evasion by Mycobacterium tuberculosis: Living with the enemy," Current Opinion in Immunology, vol. 15 , pp. 450-455, 2003

[8] J. F. Murray, "A century of tuberculosis," American Journal of Respiratory and Critical Care Medicine, vol. 11, pp. 1181-1186, Jun 2004.

[9] C. Dye and B. G. Williams, "The population dynamics and control of tuberculosis," Science, vol. 328, pp. 856-861, May 2010.

[10] K. Lonnroth, K. G. Castro, J. M. Chakaya et al., "Tuberculosis and elimination 2010-50: Cure, care and social development," The Lancet, vol. 375, pp. 1814-1829, May 2010.

[11] WHO, Global Tubeculosis Report. World Health Organization, pp. $1-98,2012$.

[12] K. Rasanathan, A. S. Kurup, E. Jaramillo, and K. Lonnroth, "The social determinants of health: key to global tuberculosis control," The International Journal of Tuberculosis and Lung Disease, vol. 15, pp. 30-36, June 2011.

[13] S. D. Lawn and A. I. Zumla, "Tuberculosis," The Lancet, vol. 378, pp. 57-72, July 2011.

[14] R. E. Chaisson and N. A. Marttinson, "Tuberculosis in Africa-combating an HIV-driven crisis," The New England Journal of Medicine, vol. 358, pp. 1089-1092, March 2008.

[15] C. Dye, "Doomsday postponed? Preventing and reversing epidemics of drug resistant tuberculosis," Nature Reviews Microbiology, vol. 7, pp. 81-87, February 2009.

[16] I. Abubakar, M. Zignol, D. Falzon et al., "Drug resistant tuberculosis: time for visionary political leadership," The Lancet Infectious Disease, vol. 13, pp. 529-539, June 2013.

[17] K. Lonnroth, E. Jaramillo, B. G. William, C. Dye, and M. Raviglione, "Drivers of Tuberculosis epidemics: The role of risk factors and social determinants," Social Science and Medicine, vol. 69, pp. 2240-2246, April 2009.

[18] J. P. Janssens and H. L. Rieder, "An ecological analysis of incidence of tuberculosis and per capita gross domestic product," European Respiratory Journal, vol. 32, pp. 1415-1416, November 2008.

[19] A. Guelar, J. M. Gatell, J. Verdejo et al., "A prospective study of the risk of tuberculosis among HIV-infected patients," AIDS, vol. 7, pp. 1345-1349, October 1993.

[20] J. W. Pape, S. S. Jean, J. L. Ho, A. Hafner, and W. D. Jr Johnson, "Effect of isoniazid prophylaxis on incidence of active tuberculosis and progression of HIV infection," The Lancet, vol. 342, pp. 268-272, July 1993.

[21] ISSN MOH/S/RAN/120.18 (AR) Annual Report, Ministry of Health Malaysia, 2017.

[22] National Strategic Plan for Tuberculosis Control, Ministry of Health Malaysia (2016-2020) October 2017.

[23] MOH/P/PAK/328.16 (GU) Clinical Practice Guideline; Management of Drug Resistant Tuberculosis ( $1^{\text {rd }}$ edition), Dec 2016

[24] ISSN MOH/S/RAN/116.18 (AR) HEALTH FACTS 2017, Ministry of Health Malaysia.

[25] D. J. Carter, P. Glaziou, K. Lonnroth et al., "The impact of social protection and poverty elimination on global tuberculosis incidence: a statistical modelling analysis of Sustainable Development Goal 1," The Lancet Global Health, vol. 6, pp. e514-e522, March 2018.

[26] M. Loef and H. Walach, "The combined effects of healthy lifestyle behaviors on all cause mortality: A systematic review and meta-analysis," Preventive Medicine, vol. 55, pp. 163-170, September 2012.

[27] WHO, Package of essential noncommunicable (PEN) disease interventions for primary health care in low-resource settings, World Health Organization, 2010. 
[28] M. E. Kruk, D. Porignon, P. C. Rockers, and W. V. Lerberghe, "The contribution of primary care to health and health systems in low- and middle-income countries: a critical review of major primary care initiatives," Social Science and Medicine, vol. 70, pp. 904-911, March 2010.

[29] J. Macinko, B. Starfield, and T. Erinosho, "The impact of primary healthcare on population health in low-and middle-income countries," The Journal of Ambulatory Care Management, vol. 32, pp. 150-171, April 2009.

[30] D. S. Kringos, W. Boerma, J. V. D. Zee, and P. Groenewegen, "Europe's strong primary care systems are linked to better population health but also to higher health spending," Health Affairs, vol. 32, pp. 686-694, April 2013.

[31] WHO, Poverty and health. World Health Organization, 2003.

[32] M. Whitehead, G. Dahlgren, and T. Evans, "Equity and health sector reforms: can low-income countries escape the medical poverty trap?' The Lancet, vol. 358, pp. 833-836, September 2001.

[33] C. G. Victora, A. Wagstaff, J. A. Schellenberg, D. Gwatkin, M. Claeson, and J. P. Habicht, "Applying an equity lens to child health and mortality: more of the same is not enough," The Lancet, vol. 362, pp 233-41, July 2003.

[34] WHO, Working for Health and Growth: Investing in the Health Workforce, Report of the high-level commission on health employment and economic growth. World Health Organization, 2016.

[35] A. Malik, M. Lenzen, S. McAlister, and F. McGain, "The carbon footprint of Australian health care," Lancet Planet Health, vol. 2, pp. e27-e35, January 2018

[36] M. J. Eckelman and J. Sherman, "Environmental impacts of the U.S. health care system and effects on public health," PLoS One, vol. 11, pp. e0157014, June 2016.

[37] WHO. (2015). The end TB strategy. World Health Organization. [Online]. Available: http://www.who.int/tb/End_TB_brochure.pdf

[38] R. M. Houben and P. J. Dodd, "The global burden of latent tuberculosis infection: A re-estimation using mathematical modelling," PLoS Medicine, vol. 13, pp. e1002152, October 2016.

[39] C. Dye, P. Glaziou, K. Floyd, and M. Raviglione, "Prospects for tuberculosis elimination," Annual Review of Public Health, vol. 34, pp. 271-286, March 2013.

[40] WHO (2018). Latent TB infection WHO fact sheet. [Online]. Available: http://www.who.int/tb/areas-of-work/preventive-care/ltbi_factsheet_2 march18.pdf?ua=1

[41] C. E. Barry, H. I. Boshoff, V. Dartois et al., "The spectrum of latent tuberculosis: Rethinking the biology and intervention strategies," Nature Reviews Microbiology, vol. 7, pp. 845-855, October 2009.

[42] N. T. Vozoris, and J. Batt, "Change in the prevalence of testing for latent tuberculosis infection in the United States: 1999-2012," Canadian Respiratory Journal, vol. 2016, 5 p., May 2016.

[43] K. Lonnroth, P. Glaziou, D. Weil, K. Floyd, M. Uplekar, and M. Raviglione, "Beyond UHC: monitoring health and social protection coverage in the context of tuberculosis care and prevention," PLOS Medicine, vol. 11, pp. e1001693, September 2014.

[44] J. R. Hargreaves, D. Boccia, C. A. Evans, M. Adato, M. Petticrew, and J. D. Porter, "The social determinants of tuberculosis: from evidence to action," American Journal of Public Health, vol. 101, pp. 654-662, April 2011.

[45] A. Siroka, N. A. Ponce, and K. Lonnroth, "Association between spending on social protection and tuberculosis burden: A global analysis," The Lancet Infectious Diseases, vol. 16, pp. 473-479, April 2016.

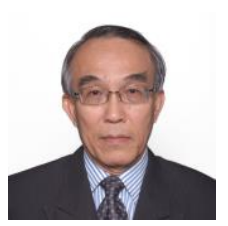

H. L. Koh received his BSc from University of Malaya in 1970 and the MA, PhD in mathematics in 1971, 1976 from University of Wisconsin, Madison, USA.

He was the recipient of Oppenheim Prize of University of Malaysia and Fulbright Scholarship USA and DAAD Fellowship. He served as an Associate Member of the International Centre for Theoretical Physics (ICTP) from 1986 to 1992 . He is currently a Senior Fellow and Professor at the Jeffrey Sachs Center on Sustainable Development in Sunway University. He has served for 40 years in Universiti Sains Malaysia before continuing his research at Sunway University. His fields of specialization include environmental/ ecological system modelling, integrated river management modelling, numerical modeling of tsunami, dengue and H1N1 epidemics. Prof. Koh has many journal publications in diverse fields.

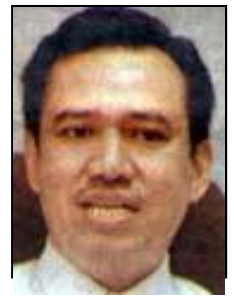

Mohamed Naim A. K. is a senior public health consultant with $\mathrm{MOH}$. Graduated from University of Malaya in 1984, attained MPH (1991). He is the current head of the National TB Control Programme, Ministry of Health. He has served in various Health Ministry's departments including Perak and Selangor State Health Office, Disease Control Division, Department of Orang Asli Development and Public Health Institute.

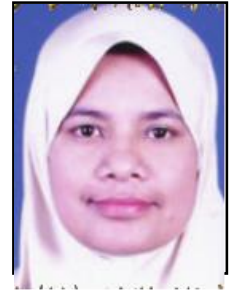

Noorliza M.N. is a senior public health consultant with MOH. Graduated from USM, attained MPH from University of Malaya (1991), MSc Health Planning Policy and Financing (LSE, LSHTM) in 1996 and Masters in Public Administration from Harvard University 2000. She served in various Health Ministry's departments including Selangor State Health Office, Disease Control Division, Planning Division, National Institutes of Health and the National Public Health Laboratory, Malaysia

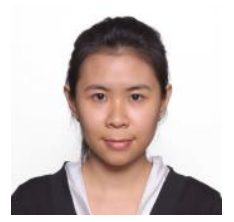

S. Y. Teh received her $\mathrm{BSc}, \mathrm{MSc}$ and $\mathrm{PhD}$ in mathematical modeling in 2004, 2005 and 2008 respectively, all from Universiti Sains Malaysia. In 2006, she was awarded the UNESCO/Keizo Obuchi Research Fellowship to undertake research at University of Miami. Since then, she has been invited to University of Miami and Nanjing Forestry University under USGS grants and to four workshops at Abdus Salam International Centre for Theoretical Physics (ICTP) at Trieste, Italy under the sponsorship of ICTP. She is currently an Associate Professor at School of Mathematical Sciences, Universiti Sains Malaysia. She is the recipient of the prestigious L'Oréal-UNESCO National Women in Science Fellowship 2017. She works on various topics in ecosystem and environmental modelling. Her research interests revolve around mathematical modelling of real-life problems to provide insights and to suggest possible solutions. Dr. Teh has many articles published in diverse fields. 